\title{
The role of EcoCampus in addressing sustainability in UK universities
}

(C) The Author(s) 2017. Published by Higher Education Press. This is an open access article under the CC BY license (http:// creativecommons.org/licenses/by/4.0)

\begin{abstract}
Universities are key drivers of sustainable development and are well-positioned to contribute to the sustainability agenda. Universities in the United Kingdom (UK) are themselves large and influential organisations, and because of their size, can have a significant impact on the environment. Their challenge, however, is to practice what they preach and to manage their own estates and procurement decisions to reduce their impact on the environment and meet carbon reduction targets. In the UK, higher education (HE) sector Scopes 1 and 2 carbon $\mathrm{CO}_{2} \mathrm{e}$ emissions have, over recent years, been falling considerably short of the emission reduction targets set by the Higher Education Funding Council for England (HEFCE) in all but a few institutions. Setting sector specific targets, therefore, does not guarantee success in addressing climate change. However, in those institutions adopting the EcoCampus management system approach, Scopes 1 and 2 carbon $\mathrm{CO}_{2} \mathrm{e}$ emissions have fallen by up to $5 \%$ over the latest reporting period (2013/2014-2014/2015). This contrasts with the increase in emissions from those institutions who currently do not have a certified management system and are currently at the bottom of the People and Planet University League Table. (This is an independent league table of UK universities ranked by environmental and ethical performance).

Environmental management systems (EMSs) are increasingly being used by organisations to improve their environmental performance. EMSs deliver many benefits such as reducing resource use and pollution, complying
\end{abstract}

Received May 4, 2017; accepted May 31, 2017

Peter REDFERN ( $₫)$

Biosciences, School of Science and Technology, Nottingham Trent University, Clifton Campus, Nottingham, NG11 8NS, UK

E-mail: peter.redfern@ntu.ac.uk

Hua ZHONG

School of Architecture, Design and Built Environment, Nottingham Trent University, City Campus, Nottingham, NG1 4FQ, UK with relevant environmental legislation, managing risks, improving corporate reputation and saving costs.

The aim of this research was to assess the carbon management performance of universities in the UK and China and relate this to the level of uptake of EMSs in these universities. The results of this research informed the development of the EMS support and awards programme called EcoCampus. EcoCampus addresses the challenges faced by universities in reducing their carbon emissions by developing an EMS in simple stages with support in a variety of different forms. This self-financing programme has now been operating successfully for over ten years. During this time, EcoCampus has worked with over 60 universities and colleges in the UK. Eighteen participants have currently achieved the highest phase of EcoCampus and certification to the international EMS standard ISO14001. There are currently 40 universities, one research institute and three colleges enrolled on the various phases of the EcoCampus programme. There are five universities from the Russell Group including Cambridge University, Imperial College London, Nottingham University, Newcastle University and University College London. The EcoCampus programme is highly successful in the UK and there is growing interest from international universities wishing to join the programme. Seven of the top ten universities in the UK's People and Planet University League Table are EcoCampus members. All the top ten universities in the League Table have shown a reduction in their carbon emissions. In contrast, the ten institutions at the bottom of the League don't have a certified EMS and have increased their carbon emissions.

By identifying the benefits of an EMS, particularly in relation to carbon management, it is hoped that this paper will encourage organisations to develop, implement and operate an EMS. This should lead to a more sustainable sector able to lead by example.

Keywords EcoCampus, environmental management, sustainable development, carbon management 


\section{Introduction}

The concentration of atmospheric carbon dioxide $\left(\mathrm{CO}_{2}\right)$ has increased from $280 \mathrm{ppm}$ (parts per million) (representative of the pre-industrial atmospheric $\mathrm{CO}_{2}$ average between the years 1000 and 1800) (Etheridge et al., 1998) to a global average of over $400 \mathrm{ppm}$, primarily due to anthropogenic greenhouse gases (GHGs) (IPCC, 2014). The last time $\mathrm{CO}_{2}$ concentrations were around $400 \mathrm{ppm}$ was during the mid-Pliocene period some 3 million years ago. In response to this rise in $\mathrm{CO}_{2}$ concentrations, the United Kingdom (UK) passed the Climate Change Act 2008, a world first in climate change regulation. This Act requires the UK to achieve a net reduction in Scopes 1 and 2 GHG emissions of $80 \%$ by the year 2050 against the baseline GHG emissions recorded in 1990 (HMSO, 2008). The Act also proposes an interim target of a $34 \%$ cut in carbon emissions by 2020 . The first and most commonly used definition for Scopes 1, 2 and 3 GHG emissions can be found in the GHG Protocol Corporate Accounting and Reporting Standard (2004). Scope 1 emissions are direct emissions within the organisational boundary from sources the organisation owns or controls, for example, the combustion of fuels on site, while Scope 2 emissions are derived from purchased electricity. Scope 3 emissions are a result of an organisation's activities, occurring from sources not owned by the organisation. Policy-makers are often reluctant to include Scope 3 emissions as part of emission reduction targets due to the difficulty of accurately monitoring the flow of emissions embedded in traded goods and services, but their significance should not be ignored. The contribution of Scope 3 emissions to overall carbon footprints is significant. In 2012, Arup, CenSA and De Montfort University conducted the HE sector's first comprehensive carbon footprint. Using data from the 2005 baseline, it was estimated that combined Scope 3 carbon emissions represented over $60 \%$ of all the sector's emissions, with construction accounting for approximately $30 \%$ of this figure (Arup, CenSA and De Montfort University, 2012).

The Higher Education Funding Council for England (HEFCE) encourages HE institutions to adopt similar targets. In 2010, the HE sector in England set challenging carbon reduction targets, specifically, a 34\% reduction in Scopes 1 and $2 \mathrm{CO}_{2} \mathrm{e}$ emissions below those recorded in 1990 , by 2020 and an $80 \%$ reduction by 2050 . This equates to a reduction of $43 \%$ using a 2005/2006 baseline (HEFCE, 2010). These targets are in line with the Climate Change Act (2008). The annual energy costs for the (HE) sector currently stands at around 400 million GBP, which equates to $\mathrm{CO}_{2} \mathrm{e}$ emissions of around $3 \times 10^{9} \mathrm{~kg}$ per year (Higher Education Estates Statistics Report, 2015). As the HE sector continues to expand, and buildings increasingly become used for extended periods, costs and $\mathrm{CO}_{2} \mathrm{e}$ emissions are predicted to increase. The Higher Education
Statistics Agency (HESA) report states that energy continues to rise in importance as an element of cost for universities.

The HEFCE strategy also requires that all English universities should report their Scope 3 emissions, including those from procurement, from 2012/2013 (HEFCE, 2010). This will present a significant challenge to the sector (Ozawa-Meida et al., 2013). Scope 3 emissions were found in one university to comprise around $79 \%$ of the total university's greenhouse gas emissions. Consequently, the HE sector has a significant impact on the environment and has demanding carbon reduction targets set by HEFCE.

In a recent study by Robinson et al. (2015) the carbon performances of twenty English Russell Group 1 universities were compared. The mean carbon reduction targets to be met by 2020 was set at circa $35 \%$ in line with the national goals. However, it was concluded that emissions during the study period had increased in all but two institutions, (these being Imperial College and the University of Birmingham) suggesting that the targets set by the institutions themselves and by HEFC are extremely ambitious.

Although between 2005/2006 to 2009/2010 there was a rise in the Russell Group carbon emissions, more recent data has shown that in the same group of universities, a reduction of $122425 \mathrm{~kg}$ of $\mathrm{CO}_{2} \mathrm{e}$ has occurred during 2014/2015 (Table 1).

Table 1 Total Scopes 1 and 2 carbon emissions between the years 2005/2006 and 2009/2010, 2009/2010 and 2014/2015

\begin{tabular}{lcc}
\hline Year & $\mathrm{CO}_{2} \mathrm{e}$ emissions $/ \mathrm{kg}$ & Change $/ \%$ \\
\hline $2005 / 2006$ & 856560000 & \\
$2009 / 2010$ & 143824000 & +17.9 \\
$2014 / 2015$ & 921389000 & -11.7 \\
\hline
\end{tabular}

Most universities are not in the Russell Group and these were not included in the paper by Robinson et al. (2015), so the results may be different.

Table 2 compares the top ten universities in the People and Planet (P\&P) University League Table with those in the bottom 10 in terms of their environmental performance (This league table is an independent league table of UK universities ranked by environmental and ethical performance). The changes for $\mathrm{CO}_{2} \mathrm{e}$ from universities in the top ten and the bottom ten P\&P University League are $-5.8 \%$ and $5.2 \%$, respectively.

The top 10 universities in the league table (seven of which are EcoCampus participants) achieved a 5.8\% reduction in their total Scope 1 and $2 \mathrm{CO}_{2} \mathrm{e}$ emissions between 2013/2014 and 2014/2015. This is in sharp contrast to an increase of 5.2\% in Scopes 1 and $2 \mathrm{CO}_{2} \mathrm{e}$ emissions for the 10 institutions ranked at the bottom of the League Table, none of which currently have a certified 
Table 2 Recent trends in total Scopes 1 and 2 carbon emissions between the years 2013/2014 and 2014/2015 in those institutions ranked in the top ten and those ranked in the bottom ten of the P\&P University League Table

\begin{tabular}{lcc}
\hline Year & $\begin{array}{c}\mathrm{CO}_{2} \mathrm{e} \text { from universities in the } \\
\text { top ten P\&P University League/kg }\end{array}$ & $\begin{array}{c}\mathrm{CO}_{2} \mathrm{e} \text { from universities in the } \\
\text { bottom ten in the P\&P } \\
\text { University League/kg }\end{array}$ \\
\hline $2013 / 2014$ & 138647000 & 25972000 \\
$2014 / 2015$ & 130403000 & 27323000 \\
\hline
\end{tabular}

EMS in place. Based on current energy prices in the UK, the reductions in Scopes1 and $2 \mathrm{CO}_{2} \mathrm{e}$ emissions would equate on average to a saving of around 123554 GBP per institution.

China is now the largest energy consumer and $\mathrm{CO}_{2}$ emitter in the world. In 2015, China's energy consumption was reported to be $4.25 \times 10^{12} \mathrm{~kg}$ of standard coal equivalent, an increase of $22 \%$ from the $3.48 \times 10^{12} \mathrm{~kg}$ consumed in 2011. China's $\mathrm{CO}_{2}$ equivalent emissions $\left(\mathrm{CO}_{2} \mathrm{e}\right.$, including all six major GHGs) has now reached $9 \times 10^{12} \mathrm{~kg}$, or $28 \%$ of the world's total emissions (National Bureau of Statistics of China, 2016). China continues to urbanise and modernise, so even its size-normalised $\mathrm{CO}_{2}$ emissions are growing rapidly.

The challenges posed by climate change are some of the most difficult to overcome and give rise to high levels of anxiety. In China, young people are particularly pessimistic about the threat of climate change. A recent survey by the Varkey Foundation (2017) found that $87 \%$ of young people in China (a significantly higher percentage than in any other country) are more concerned about climate change than any other issue. The education sector in China is well placed to address this issue and bring about a positive change. Li et al. (2015) surveyed student's energy consumption patterns, which proved to serve two roles, one to increase student awareness of GHG emissions and secondly to assist in campus-wide decision making. They concluded that the current low (3.84 t $\mathrm{CO}_{2} \mathrm{e}$ per student) carbon footprint is due to poor student comfort and basic needs and they predicted that as China continues to develop, the average student carbon footprint will rise modestly.

As in the UK, universities in China could help to reduce carbon emissions by changing the way they operate, and perhaps more importantly, by influencing student behaviour. Limited evidence suggests that energy consumption is increasing in some Chinese universities. Between 2013/ 2014 and 2014/2015, there was a rise in electricity and gas energy consumption of over $2 \%$ in three universities where data was made available (Table 3). The changes of $\mathrm{CO}_{2}$ of
Universities $\mathrm{T}, \mathrm{H}$, and $\mathrm{Z}$ are $+2.17 \%,+2.17 \%$, and $+2.66 \%$, respectively.

The higher education sector in China is experiencing significant growth and currently, there are more than 2852 universities with 36.47 million students (Ministry of Education 2016). Universities account for approximately $10 \%$ of the total energy consumption in China.

As the HE sectors in the UK and China continue to grow, so will their $\mathrm{CO}_{2}$ emissions. From the UK, there is evidence that universities that have an EMS are more successful in reducing carbon emissions than those that don't have one. EMSs are increasingly being used by organisations to improve their environmental and sustainability performance by the process of continual improvement (Psomas et al., 2011). EMSs are being used to manage environmental aspects i.e., the elements of an organisation's activities or products or services that interact, or can interact, with the environment (ISO 14001, 2015). They address areas such as pollution, waste, energy, water, transport, carbon emissions, legal compliance and procurement.

EMSs are being increasingly used as the environmental and economic impacts of climate change become more apparent (Stern, 2007; Stern, 2008; UNFCCC, 2015). The major benefits of developing an EMS are that it:

- assists in obtaining a licence to operate and fulfilling compliance obligations;

- improves relationships with regulators;

- helps to prevent enforcement or civil actions;

- reduces hidden costs associated with legal action (including a substantial draw on management time);

- avoids fines and damages awarded through criminal or civil courts;

- improves operational and process efficiency;

- reduces operating costs and resource use thereby increasing profitability;

- reduces outlay on waste disposal;

- gives the organisation a long-term sustainable future;

- reduces pollution and improves the environment;

- helps to mitigate the effects of climate change;

Table 3 Recent trends in carbon emissions between the years 2013/2014 and 2014/2015 in three of the Project 985 Chinese institutions, which represent the leading higher education institutions in China

\begin{tabular}{lccc}
\hline Year & $\mathrm{CO}_{2} \mathrm{e}$ of University T/kg & $\mathrm{CO}_{2} \mathrm{e}$ of University H/kg & $\mathrm{CO}_{2} \mathrm{e}$ of University Z/kg \\
\hline $2013 / 2014$ & 16726090 & 14070270 & 34715900 \\
$2014 / 2015$ & 17299340 & 14382170 & 35664840 \\
\hline
\end{tabular}


- develops relationships with stakeholders by satisfying investors' lenders' and insurers' environmental performance requirements;

- helps to obtain insurance at a reasonable cost;

- enhances the internal and external image of the organisation, making it more marketable;

- helps attract and retain quality staff.

Despite the acknowledged benefits of an EMS (Fisher, 2003), a considerable number of universities and colleges in the UK still consider the implementation of an EMS, in line with standards such as ISO 14001 (2015), EMAS The Eco-Management and Audit Scheme (2016) or BS 8555 (2003), a daunting and expensive process. Like other large complex organisations, universities and colleges often must overcome several barriers before they can improve their overall environmental performance (Dahle and Neumayer, 2001) using an EMS approach. Hence, the main aim of the research was to investigate how universities in the UK could be helped to develop and operate an EMS.

\section{Aims}

The aims of this research were to:

- discover the level of uptake of EMSs in the HE sector in the UK;

- investigate the drivers for developing an EMS;

- identify the barriers that universities face in developing, implementing and operating an EMS;

- develop a programme and resources for overcoming the barriers;

- monitor the uptake of the programme;

- assess the effectiveness of the programme.

\section{Methods}

The first step was to conduct extensive research to identify the uptake of EMSs in the HE sector, the drivers for developing an EMS and the barriers preventing the development of an EMS. This took the form of an online survey of the UK HE and Further Education (FE) sectors. The survey was designed and conducted to optimise the response rate (Burgess, 2001; Bryman and Bell, 2007) with 27 questions grouped into four broad categories. The results from this survey were analysed and are presented in the results section.

The survey findings were used to design a programme of support to overcome the barriers to EMS adoption. This programme was piloted, refined and then rolled out into the sector. The current state of the programme was researched and the results are presented. Data analysis was also carried out on the HESA (Higher Education Estates Statistics Report, 2015) statistics for the universities ranked in the top ten and those in the bottom ten of the People and Planet University League Table (People and Planet, 2017).

\section{Results}

110 universities and colleges completed the online survey. (It should be noted that the responses given are an individual's personal opinion and may not be a true representation of their institution's views.) The survey canvassed the opinion of $52 \%$ of the UK HE sector and approximately $18 \%$ of the combined HE and FE sectors in total.

Firstly, the survey sought to discover the extent of the uptake of EMSs in HE institutions (Fig. 1). It was found that $8 \%$ of HE institutions already had an EMS in place and that $59 \%$ were in the process of developing an EMS. The research showed that $15 \%$ of universities had no intention of developing an EMS. Most of the remaining 18\% of universities indicated that, while they were in favour of EMSs, they currently lacked the resources to develop an EMS.

The survey also sought to discover what was driving the growing interest amongst HE institutions in EMSs. The two most important drivers were cost savings $(20 \%)$ and institutional reputation (20\%) (Fig. 2). This was followed closely by regulatory compliance (19\%) and the promotion of environmental stewardship (17\%). Stakeholder opinion $(11 \%)$ and sector benchmarking (9\%) were of similar importance with $4 \%$ stating wider community pressures as

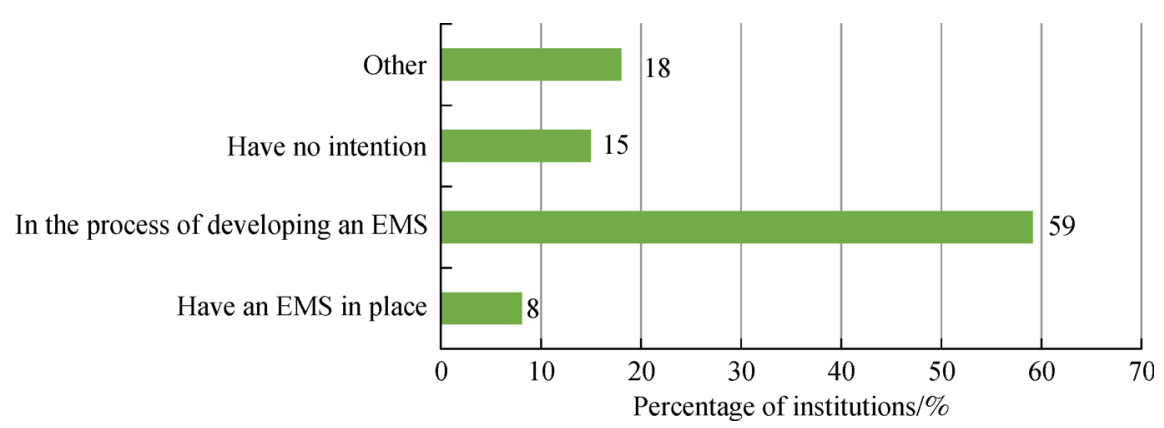

Fig. 1 The uptake of EMSs in HE institutions 


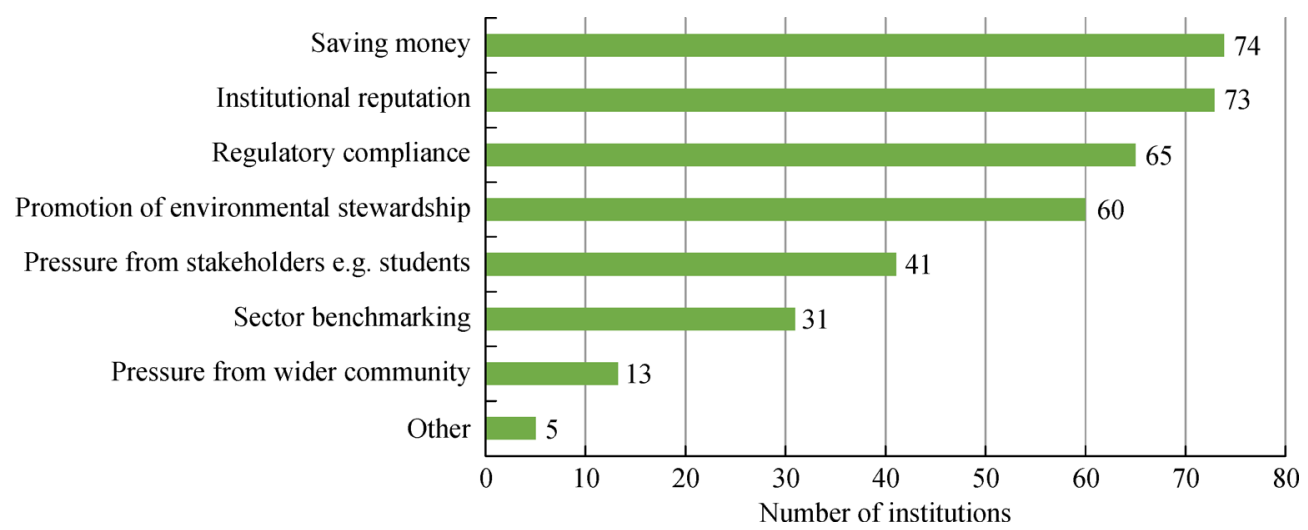

Fig. 2 Drivers for developing an EMS

being important. Just $1 \%$ of respondents identified other drivers.

As part of the survey, institutions were also asked to give their opinion on the most significant barriers to developing an EMS (Fig. 3). A lack of human and financial resources followed by a lack of time and knowledge were given as the most important barriers.

The results of the survey identified the current level of uptake of EMSs in UK universities, the drivers for developing an EMS and the barriers preventing the development of an EMS. These results were used to help develop the EcoCampus programme (www.ecocampus.co. uk), which enables universities and colleges to develop, implement, operate and audit an EMS in four phases. The process of developing an EMS was split into a series of steps to make the process less daunting. Four awards (Bronze, Silver, Gold and Platinum) with auditable criteria assess performance, acknowledge progress made and encourage continued participation. Within each of the four phases, there are a number of steps that must be completed to meet the scheme's requirements. These are outlined in Fig. 4.

EcoCampus has also designed training materials and workshops to up-skill the key staff in universities with the roles and responsibility for developing an EMS and to enable them to share best practice. A series of software tools were developed to assist with the more challenging aspects of developing, operating and auditing an EMS and making the process as simple and efficient as possible.

Initially, the EcoCampus programme was piloted with 10 institutions funded by HEFCE. This pilot study was used to refine the programme in the light of experience. Because EcoCampus was so well received by the sector, it was rolled out in 2005 as a self-funding programme and has been operating successfully ever since.

Since its inception, EcoCampus has worked with over 60 universities and colleges. Eighteen of the participating institutions have achieved the Platinum Phase of EcoCampus and certification to the international EMS standard ISO14001. These include: Aston University, Bath Spa University, Birkbeck College, Birmingham City University, Bournemouth University, Canterbury Christ Church University, City University London, Glasgow Caledonian University, Institute of Cancer Research, London School of Economics and Political Science, Newcastle University, Nottingham Trent University, Swansea University, The Manchester Metropolitan University, University of East Anglia, University of Bradford, University of Hertfordshire, University of Reading, University of Southampton, and the University of Worcester. There are currently 40

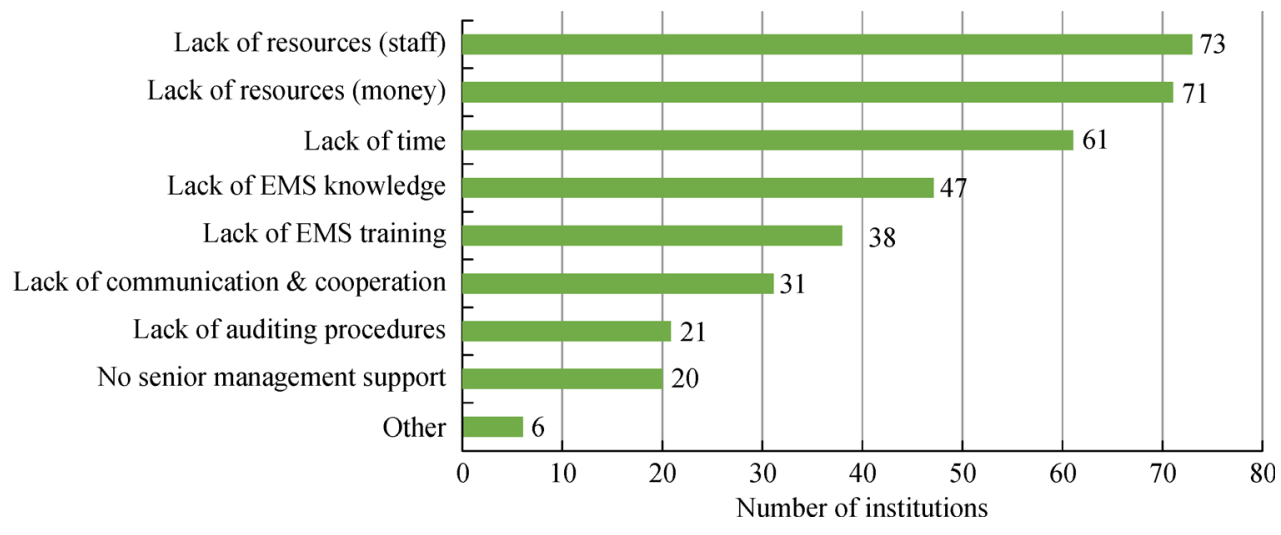

Fig. 3 Barriers to the development of an EMS 


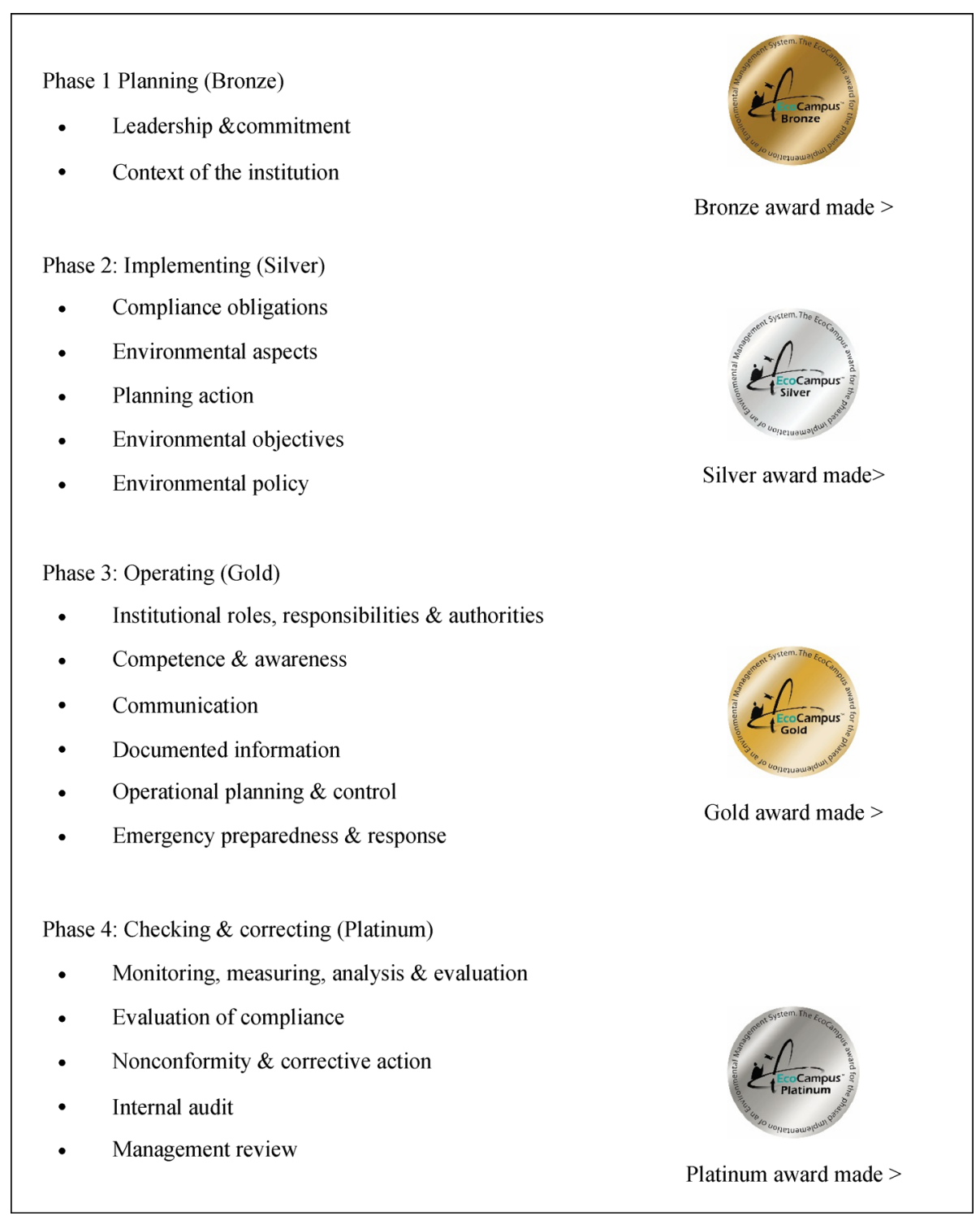

Fig. 4 The four phases of the EcoCampus scheme, associated auditable steps and awards (Bronze, Silver, Gold and Platinum)

universities, 1 research institute and 2 colleges enrolled on the EcoCampus programme: 18 at Platinum; 7 at Gold; 11 at Silver; 4 at Bronze, and 3 just beginning. Universities from the Russell Group include Cambridge University, Imperial College London, Nottingham University, Newcastle University and University College London.

\section{Conclusions}

The results of the survey showed that only $8 \%$ of HE institutions had an EMS in place and that 59\% were in the process of developing an EMS. A similar survey carried out during 2006, on behalf of the Campus Consortium for Environmental Excellence (Bryman and Bell, 2007), The 2006 Benchmark Survey of the State of the Environmental Management Systems at Colleges and Universities (C2E2,
2006), found that in the USA, just fewer than $16 \%$ of HE institutions had an EMS in place, double the number in the UK. While in the USA, 25\% were developing an EMS, $14 \%$ of universities indicated that they had no current intention of developing an EMS, which is like the $15 \%$ of universities in the UK who were not currently considering developing an EMS. Just fewer than 38\% indicated that they had an interest in developing an EMS, while $8 \%$ of the respondents answered "other" to the question: "What is the present state of your institution's EMS." A survey on the adoption of environmental management systems at colleges and universities in the USA, conducted by Savely, Carson and Delclos in 2005 (Savely et al., 2006), found that over $50 \%$ of the respondents had environmental programmes that were well developed, with some $30 \%$ expressing the view that they had implemented an EMS along the lines of ISO 14001. 
In conclusion, the results from the present study, as well as other studies in the UK and the USA, suggest that there is a growing knowledge and uptake of EMSs in the HE sector. However, there are perceived and real barriers to developing an EMS identified by the sector. The major barriers identified in the survey were a lack of human and financial resources and a lack of time and knowledge. Building upon the results of the survey and discussions with HEFCE and institutions within the sector, EcoCampus was tailored to overcome these barriers. EcoCampus has been very successful in recruiting institutions into the programme and helping them to develop an EMS, with all the benefits that this brings, as was outlined in the introduction.

Throughout the project, extensive feedback was collected from participating institutions and this was used to refine and develop the programme. This is an ongoing process and there is continual change to keep EcoCampus in line with the international EMS standard, changing environmental legislation and the views of interested parties. There is evidence to suggest that EMSs provide a good framework for integrating environmental protection policies, programs and practices into an organisation (Morrow and Rondinelli, 2002). This approach in universities and colleges should be encouraged to reduce their impact on the environment. This is best achieved in a logical and efficient way by operating an EMS. By improving their own environmental performance and through their procurement policies, they can be exemplars of best practice and make a real difference. Operating an EMS will also save institutions money, improve their operational efficiency and enhance their reputation. The figures presented in Table 2 indicate that carbon reductions and financial savings equating to around 123554 GBP per institution can be made. The EcoCampus programme has been highly successful in helping universities and colleges to develop an EMS and improve their environmental and sustainability performance.

Universities and colleges should set a good example to their students through the measures they are taking to improve their own environmental performance. The HE sector in the UK educates around two million students each year. Consequently, the HE sector can have a significant impact on students' knowledge, understanding and the adoption of sustainable development principles. Many of these students will be the decision makers of the future and their education can influence their wish to protect the environment in their personal life and future careers.

Education for sustainable development should be holistic and interdisciplinary and while this has not been the central role of EcoCampus, it does hold the potential to provide experiential learning which will enable students to solve real-world problems and acquire professional knowledge, skills and experience. The bridge between the academic, societal and business world that can be forged by the implementation of an EMS within universities has been highlighted elsewhere (Ferreira et al., 2006; Sammalisto and Brorson, 2006).

EcoCampus has been used in several programmes of study to enable students to gain an appreciation of the interdisciplinary nature of environmental management alongside knowledge of people, processes and practice that is increasingly required by future employers. It is widely acknowledged that individuals and organisations should be able to make informed decisions based on a better understanding of the links between our everyday decisions and their local and global outcomes. Consequently, many institutions have become signatories to charters like Copernicus (Copernicus Charter, 1994) and have made a commitment to address sustainable development in courses, research and operational management.

EcoCampus is currently investigating how it can further help the sector to embed education for sustainable development in the curriculum, for example, through the provision of online modules on sustainable development that can be used across whole institutions.

EcoCampus has the potential to help all educational institutions in the UK and internationally to improve their environmental performance using a management system approach. It can help them to reduce their consumption of resources, reduce pollution, comply with relevant environmental legislation, manage risks, improve their reputation, save costs and reduce total Scopes 1 and $2 \mathrm{CO}_{2} \mathrm{e}$ emissions.

Setting sector specific carbon reduction targets does not guarantee that they will be achieved. However, in those institutions adopting the EcoCampus (management system) approach, both Scopes 1 and 2 carbon $\mathrm{CO}_{2} \mathrm{e}$ emissions have fallen by up to $5 \%$ contrasting with the increase seen in emissions from those institutions who currently do not have a certified management system in place. The EcoCampus approach gives institutions the structure and tools required to improve their environmental performance.

In the future, it is hoped that EcoCampus can help other institutions in the UK and abroad to meet their carbon reduction targets, embed sustainable development principles in the curriculum and empower their students to make a difference.

Acknowledgements The authors would like to thank the many individuals and organisations who have given their time and ideas to the development of EcoCampus. The initial EcoCampus pilot was funded by Environmental Campaigns (ENCAMS) and the Higher Education Funding Council for England (HEFCE) and led by Nottingham Trent University in collaboration with 10 Higher Education Institutions and Loreus Ltd.

\section{References}

Arup, CenSA and De Montfort University (2012). Measuring scope 3 carbon emissions: Supply-chain (procurement): Report to HEFCE on sector emissions by Arup, CenSA and De Montfort University. 
Cheltenham: HESA. http:/www.hefce.ac.uk/pubs/rereports/year/ 2012/scope3carbon/, 2017-6-19

Bryman A, Bell E (2007). Business Research Methods. 2nd ed. New York: Oxford University Press

BS 8555 (2003). Environmental management systems. Guide to the phased implementation of an environmental management system including the use of environmental performance evaluation. http:// shop.bsigroup.com/ProductDetail/?pid $=000000000030077920$

Burgess T F (2001). Information Systems Services, Guide to the Design of Questionnaires Edition 1.1 University of Leeds

C2E2 (2006). The 2006 Benchmark Survey of the State of the Environmental Management Systems at Colleges and Universities. Report to the Campus Consortium for Environmental Excellence. http://c2e2.org/Documents/OriginalC2E2Documents/2006_EMS_Report.pdfm, 2017-6-19

Climate Change Act (2008). http://www.legislation.gov.uk/ukpga/2008/ 27/contents, 2017-6-19

Copernicus Charter (1994). The University Charter of Sustainable Development of the Conference of European Rectors (CRE), Genèva

Dahle M, Neumayer E (2001). Overcoming barriers to campus greening: A survey among higher educational institutions in London, UK. International Journal of Sustainability in Higher Education, 2(2): 139-160

Etheridge D M, Steele L P, Langenfelds R L, Francey R J, Barnola J M, Morgan V I (1998). Historical $\mathrm{CO}_{2}$ records from the Law Dome DE08, DE08-2, and DSS ice cores. In Trends: A Compendium of Data on Global Change. Carbon Dioxide Information Analysis Center, Oak Ridge National Laboratory, U.S. Department of Energy, Oak Ridge, Tenn., U.S.A

EMAS - The Eco-Management and Audit Scheme (2016). http://eurlex.europa.eu/legal-content/EN/TXT/?uri = CELEX:32009R1221, 2017-6-19

Ferreira A J D, Lopes M A R, Morais J P F (2006). Environmental management and audit schemes implementation as an educational tool for sustainability. Journal of Cleaner Production, 14(9-11): 973982

Fisher R M (2003). Applying ISO 14001 as a business tool for campus sustainability: A case study from New Zealand. International Journal of Sustainability in Higher Education, 4(2): 138-150

GHG Protocol Corporate Accounting and Reporting Standard (2004). World Resources Institute and World Business Council for Sustainable Development. http://www.ghgprotocol.org/corporate-standard, 2017-6-18

Higher Education Estates Statistics Report (2015). http://www.aude.ac. uk/documents/highereducation-estates-statistics-report-2015, 2017 6-19

Higher Education Funding Council for England (2010). Carbon management strategies and plans: A guide to good practice. HEFCE, Bristol. http://www.hefce.ac.uk/pubs/year/2010/201002/,
2017-6-19

HMSO (2008). http://www.legislation.gov.uk/ukpga/2008/27/contents, 2017-6-19

IPCC (2014). Climate Change 2014: Synthesis Report. Contribution of Working Groups I, II and III to the Fifth Assessment Report of the Intergovernmental Panel on Climate Change. IPCC, Geneva, Switzerland, 151

ISO 14001 (2015). Environmental management systems. Requirements with guidance for use. https://www.iso.org/obp/ui/\#iso:std: iso:14001:ed-3:v1:en, 2017-6-19

Li X, Tan H, Rackes A (2015). Carbon footprint analysis of student behaviour for a sustainable university campus in China. Journal of Cleaner Production, 106: 97-108

Ministry of Education (2016). Bulletin of National Education Statistics

Morrow D, Rondinelli D (2002). Adopting corporate environmental management systems: Motivations and results of ISO 14001 and EMAS certification. European Management Journal, 20(2): 159-171

National Bureau of Statistics of China (NBSC) (2016). http://www.stats. gov.cn/tjsj/ndsj/2016/indexeh.htm, 2017-6-19

Ozawa-Meida L, Brockway P, Letten K, Davies J, Fleming P (2013). Measuring carbon performance in a UK University through a consumption-based carbon footprint: De Montfort University case study. Journal of Cleaner Production, 56: 185-198

People and Planet (2017). https://peopleandplanet.org/university-league, 2017-6-19

Psomas E L, Fotopoulos C V, Kafetzopoulos D P (2011). Motives, difficulties and benefits in implementing the ISO 14001 Environmental Management System. Management of Environmental Quality: An International Journal, 22(4): 502-521

Robinson O, Kemp S, Williams I (2015). Carbon management at universities: A reality check. Journal of Cleaner Production, 106: 109-118

Sammalisto K, Brorson T (2006). Training and communication in the implementation of environmental management systems (ISO 14001). A case study at the University of Gävle, Sweden. Journal of Cleaner Production, 29

Savely S M, Carson A I, Delclos G L (2007). A survey of the implementation status of environmental management systems in U.S. colleges and universities. Journal of Cleaner Production, 15 (7): 650659

Stern N (2007). The Economics of Climate Change: The Stern Review. Cambridge: Cambridge University Press

Stern N (2008). Key Elements of a Global Deal on Climate Change. London School of Economics and Political Science

The Varkey Foundation (2017). http://www.varkeyfoundation.org, 20176-19

UNFCCC (2015). http://unfccc.int/documentation/documents/advanced_search/items/6911.php?priref $=600008831,2017-6-19$ 